\title{
Slow potential changes recorded from human brain during learning of a temporal interval
}

DALE W. MCADAM

DEPARTMENT OF PSYCHIATRY, UNIVERSITY OF IOWA

The contingent negative variation (CNV), a cerebral DC shift in man, has been linked in the literature to the psychological concept "expectancy." In a study of the relationship between developing accuracy of interval estimation and CNV amplitude, absolute error of interval estimation was found to decrease exponentially while CNV amplitude could best be described by a quadratic (inverted-u) function. It was concluded that the relationship between CNV amplitude and "expectancy" is not one-to-one, and that these data, with those from a number of other investigations, support the hypothesis that the various portions of the brain act differentially and at various times during learning.

The "contingent negative variation" (CNV) is a slow potential change, negative at vertex with respect to mastoid, which was shown originally by Walter, Cooper, Aldridge, McCallum \& Winter (1964) to occur during the foreperiod between warning signal and stimulus in a reaction time experiment. Various techniques have been used to demonstrate the neural origin of the CNV and to link it to such psychological concepts as "conation" (Low, Borda, Frost, \& Kellaway, 1966; McAdam, Irwin, Rebert, \& Knott, 1966), "motivation"' (Irwin, Knott, McAdam, \& Rebert, 1966; Rebert, McAdam, Knott, \& Irwin, 1966) and "expectancy" (Walter, 1964). "Expectancy," an associational variable, is related to the learning of the interval between warning signal and stimulus in a reaction time experiment. The present investigation was undertaken to determine the relationship between CNV development and learning to estimate precisely a short interval of time. The only published evidence on this relationship was collected in a classical defensive eyelid conditioning situation (Walter et al, 1964), and the authors point out the possible contaminating effect on the results of avoidance of the unconditioned stimulus (in their situation) coincident with the performance of the conditioned response. Method

Ss were nine women between the ages of 18 and 29 , all either laboratory technicians or secretaries. Some had served previously in other studies of the CNV. They were seated in a comfortable chair in a semi-soundproofed room, and $\mathrm{Ag}-\mathrm{AgCl}$ electrodes (specially prepared and selected for low drift) were secured with collodion at vertex and over the right mastoid. A third electrode on the forehead served as a ground. EEGs were recorded using a Grass Model 7P1 DC preamplifier and a Model 7 polygraph. Electroenchephalographic responses were averaged in blocks of five trials using a Nuclear Data ND-800 Enhancetron, and the averages read out on a second channel of the polygraph. A $200 \mathrm{cps}$ tone (ca. $65 \mathrm{~dB}$ above ambient noise) was the only stimulus used. The Ss were instructed to turn the tone off by pressing a telegraph key $1.5 \mathrm{sec}$. after its onset. They were further told to do this without "counting," i.e., without breaking the interval into segments, and to make no movements other than pressing the key. All Ss sat quietly with eyes closed throughout the experiment. After each trial E told S whether she was "over," "under" or "on" the $1.5 \mathrm{sec}$. interval. Responses in the range from 1400.0 to 1599.9 were reported as "on." Fifty trials were given at intervals of from 10 to $30 \mathrm{sec}$. Response times were scored by gating a Computer Measurements Corporation Model 1125A frequency counter between the tone onset and the response. The $10 \mathrm{kc}$ internal frequency source of the counter was used, allowing response times to be measured to the nearest msec.

Slow potential changes were evaluated by measuring the difference between the peak post-stimulus negativity and the pre-stimulus baseline in millimeters. Subsequent comparison of this measure with a known calibration voltage allowed the expression of CNV amplitude in $\mu \mathrm{V}$.

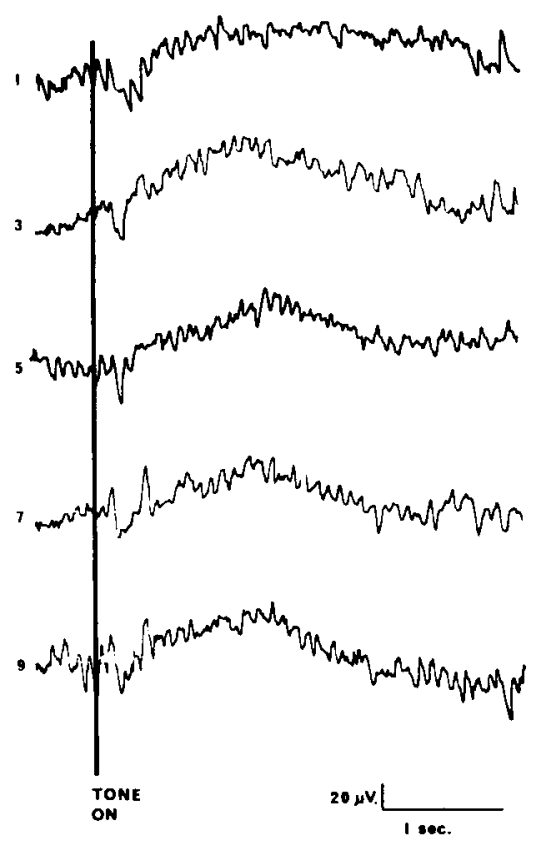

Fig. 1. Examples of CNVs from odd-numbered blocks of trials for one subject. Negativity at vertex with respect to mastoid is represented as an upward deflection. 


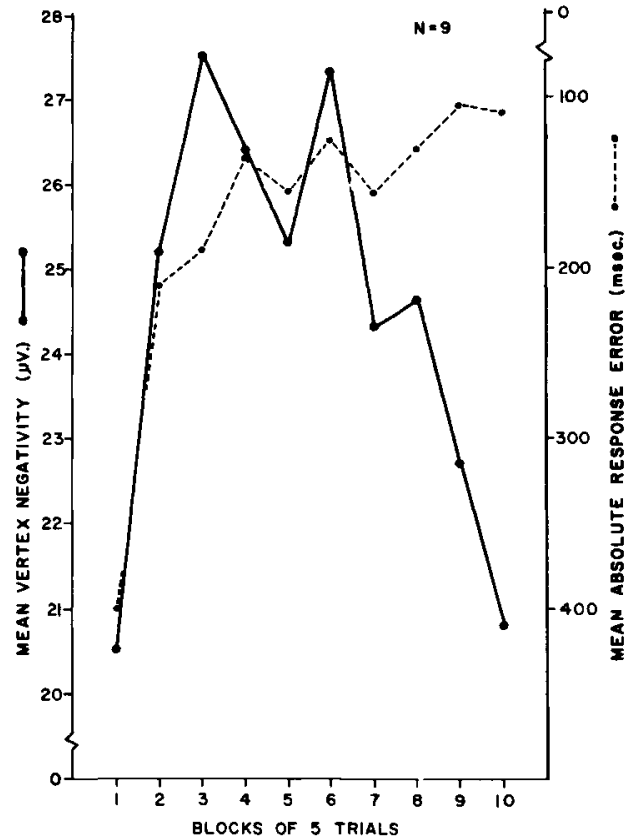

Fig. 2. Mean CNV amplitude (left ordinate, solid line) and mean absolute response time error (right ordinate, dashed line) plotted over blocks of 5 trials.

\section{Results}

CNVs from the odd numbered blocks of trials for one $\mathrm{S}$ are presented in Fig. 1. The $\mathrm{CNV}$ is seen as a vertex negative response growing out of the evoked response to tone onset. That the sudden release of this negativity reported by others is not seen here is probably due to the fact that a second stimulus (for which the response was substituted in the present study) did not occur at any discrete moment in time. Figure 2 presents a plot of CNV amplitude and absolute response error against blocks of five trials. When tested by a related $\mathrm{t}$ test (one tailed hypothesis), the differences between CNV amplitudes on both the first and last blocks of trials and those seen during blocks 3,4 , and 6 were statistically significant $(p<.05)$. A test for trend using the method of orthogonal polynomials demonstrated that the only statistically significant component was the quadratic ( $F=9.35, d f=1 / 72, p<.005)$, indicating that the curve could best be fitted with an inverted$\mathrm{U}$ shaped function. Figure 2 also presents the mean absolute response error over blocks of trials. Analysis of variance yielded a significant trials effect $(F=7.97$, df $=9 / 72, p<.001$ ), and further demonstrated significant departures from linearity and the quadratic. A plot of $\log$ (response time error $+c$ ) against trials appeared linear, indicating that an exponential (hence, monotonic) equation would best fit this curve.

\section{Discussion}

These results indicate that the growth of the CNV amplitude and of the learning of the interval tend to be parallel during the early and middle stages of learning, but that, as asymptote of performance is approached, there is a decline in CNV amplitude. Thus, a simple one-to-one relationship between CNV and "expectancy" can not be supported, since as "expectancy" becomes highly precise, CNV magnitude declines.

Inverted-U functions relating cerebral eletrophysiological responses and learning are not uncommon (Beck, Doty, \& Kooi, 1958; Chiorini, 1966; Grastyan, Lissak, Madarasz, \& Donhoffer, 1959; John \& Killam, 1957; McAdam, Knott, \& Ingram, 1962; McAdam, 1962). The present data provide further support for the hypothesis that various portions of the brain play their roles at various times during the course of learning, and, hence, electrophysiological "learning curves" are the exception rather than the rule (McAdam, 1962).

\section{References}

Beck, E. C., Doty, R. W., \& Kooi. Electrocortical reactions associated ${ }^{*} \cdot$ th conditioned flexion reflexes. EEG clin. Neurophysiol. 1958,1 , 279-289.

Chiorini, J. R. Slow potential changes from cat cortex during classical aversive conditioning. Unpublished Dissertation, University of lor a (Psychology), 1966.

Grastyan, E., L'ssak, K., Madarasz, I., \& Donhoffer, H. Hippocampal electrical activity during the development of conditioned reflexes. EEG clin. Neurophysiol., 1959, 11,.409-430.

Irwin, D. A., Knott, J. R., McAdam, D. W., \& Rebert, C. S. Motivational determinants of the "Contingent Negative Variation." EEG clin. Neurophysiol., 1966, in press.

John, E. R., \& Killam, K. F. Electrophysiological correlates of avoidance conditioning in the cat. J. Pharmacol. exp. Ther. $1959,125,252-274$

Low, M. D., Borda, R. P., Frost, J. D., \& Kellaway, P. Surfacenegative, slow-potential shift associated with conditioning in man. Neurology, 1966, 16, 771-782.

McAdam, D. W. Electroencephalographic changes and classical aversive conditioning in the cat. Exp. Neurol., 1962, 6, 357-371.

McAdam, D. W., Irwin, D. A., Rebert, C. S., \& Knott, J. R. Conative control of the contingent negative variation. EEG clin. Neurophysiol., 1966, 21, 194-195.

McAdam, D. W., Knott, J. R., \& Ingram, W. R. Changes in EEG responses evoked by the conditioned stimulus during classica aversive conditioning in the cat. EEG clin. Neurophysiol., 1962 14, 731-738.

Rebert, C. S., McAdam., D. W., Knott, J. R., \& Irwin, D. A. A slow potential change in human brain related to level of motivation. J. comp. physiol. Psychol, 1966, in press.

Walter, W. G. Slow potential waves in the human brain associated with expectancy, attention and decision. Arch. Psychat. Ner venkr., 1964, 206, 309-322.

Walter, W. G., Cooper, R., Aldridge, V. J., McCallum, W. C., \& Winter, A. L. Contingent negative variation: an electric sign of sensorimotor association and expectancy in the human brain. Nature, London, 1964, 203, 380-384. 